\title{
A new perspective on COPD exacerbations: monitoring impact by measuring physical, psychological and social resilience
}

\author{
Martijn A. Spruit ${ }^{1}$, Frits M.E. Franssen ${ }^{1}$, Erica P.A. Rutten ${ }^{1}$, Suzan Wopereis ${ }^{2}$, \\ Emiel F.M. Wouters ${ }^{1}$ and Lowie E.G.W. Vanfleteren ${ }^{1}$
}

Affiliations: ${ }^{1}$ Dept Research and Education, CIRO, center of expertise for chronic organ failure, Horn, The Netherlands. ${ }^{2}$ Microbiology and Systems Biology, Netherlands Organization for Applied Scientific Research (TNO), Zeist, The Netherlands.

Correspondence: Martijn A. Spruit, CIRO, center of expertise for chronic organ failure, Dept Research and Education, Hornerheide 1, 6085 NM, Horn, The Netherlands. E-mail: martijnspruitaciro-horn.nl

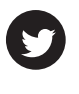

@ERSpublications

Monitoring the impact of COPD exacerbations by measuring physical, psychological and social resilience http://ow.ly/VCjRC

In 2011, Huber et al. [1] defined health as "the ability to adapt and self-manage in the face of social, physical, and emotional challenges". This definition seems very useful to monitor or even predict the impact of exacerbations of chronic obstructive pulmonary disease (COPD), or the so-called lung attacks.

Exacerbations of COPD (defined as "a sustained worsening of the patient's condition, from the stable state and beyond normal day-to-day variations, that is acute in onset and necessitates a change in regular medication in a patient with underlying COPD" [2]) are typically stressful events in the natural history of COPD, characterised by a worsening of the lung function, more symptoms of cough, dyspnoea and sputum, increased airway inflammation, increased systemic inflammation, and flare-ups of cardiovascular and metabolic medical conditions [3-5]. It is generally assumed that these exacerbations are largely triggered by viral and/or bacterial respiratory infections, or irritants [6]. Although patients with very severe COPD (Global Initiative for Chronic Obstructive Lung Disease (GOLD) stage IV) are most susceptible to exacerbations, exacerbations also frequently occur in patients with a moderate degree of airflow limitation (GOLD stage II) [7].

Large heterogeneity exists in the clinical presentation of COPD exacerbations (with or without infection/ fever, sputum purulence, etc.), and severity of exacerbations ranges from increased daily symptoms up to prolonged ventilator support due to acute respiratory failure. During these episodes of lung attacks, patients need additional help with the performance of simple, domestic tasks (i.e. personal hygiene, toileting, dressing and household chores); in nearly half of patients all daily activities are stopped [8] and $\sim 90 \%$ of patients (partially) rely on help from others in the performance of general household chores like cooking and shopping [9]. Patients report multiple adverse feelings, including depression, irritability, bad temper, guilt, anxiety, and worries about suffocating and dying; patients stop socialising during an exacerbation [8, 10]; and more depressive symptoms occur in the partners of patients with $\geqslant 2$ exacerbations or $\geqslant 1$ hospitalisation [11]. So, exacerbations of COPD result in physical, emotional and social challenges that patients and their (resident) relatives need to deal with. Indeed, patients with COPD may suffer from post-traumatic stress syndrome symptoms following an exacerbation, in particular those patients needing hospitalisation [12].

Continuously preserving patient's health necessitates the ability to adapt to challenges using response reactions aimed at regaining social, physical and emotional homeostasis [13]. In the context of a given

Received: Oct 062015 | Accepted: Dec 022015

Conflict of interest: Disclosures can be found alongside the online version of this article at erj.ersjournals.com

Copyright $\odot$ ERS 2016 
"severity" of exacerbation and in the absence of precise pathophysiologically driven management strategies, the patients with: the best protective innate and adaptive immune response; the best response to pharmacological and non-pharmacological therapy; a sense of coherence; a sense of manageability; and the best capability to adjust to the exacerbation will most probably experience less stress and a faster recovery, and in turn, better health (figure 1, solid green line). Indeed, these patients are assumed to have the best physical, psychological and/or social "resilience". By contrast, those patients with COPD who only partially recuperate to pre-exacerbation stress levels seem to have impaired health (i.e. an insufficient ability to adapt and self-manage the social, physical and/or emotional challenges of a COPD exacerbation) (figure 1, solid red line).

To date, only a few observational studies have studied the physical reaction to a COPD exacerbation, using serial measurements of lung function [14-16], daily symptoms cards [16], exhaled nitric oxide concentrations [17], or high-sensitivity cardiac troponin T [18]. All studies show a large heterogeneity in patients' reactions to an exacerbation. Besides the degree of severity of COPD exacerbations, these findings emphasise that physical resilience will play an important role in recovery following exacerbations. It seems also very reasonable to hypothesise that psychological and social resilience play an important role in the impact of an exacerbation of COPD [19]. Indeed, a defect in the challenge response reaction in one or more of these domains most likely impairs the recovery process, and, in turn, the patient's health [20].

Collaborative self-management programmes should be considered in all patients, as this generally improves quality of life and reduces respiratory-related hospital admissions [21]. However, the optimal format (i.e. form, content and duration) remains to be elucidated [21]. The patients with a late recovery to pre-exacerbation stress levels (figure 1, solid blue line) or with a defect in the recovery process (figure 1, solid red line) seem excellent candidates for a comprehensive pulmonary rehabilitation programme, including exercise training, collaborative self-management strategies, smoking cessation, nutritional counselling, diagnosis and treatment of comorbidities, and psychosocial counselling [22]. Pulmonary rehabilitation most probably will increase patient's physical, psychological and social resilience, and, in turn, lower the impact of a COPD exacerbation (figure 1, dotted red and blue lines). For example, physical resilience (as measured using the oxidative stress reaction to a maximal and submaximal exercise test) improved significantly after an 8-week pulmonary rehabilitation programme in patients with clinically stable COPD [23]. Interestingly, pulmonary rehabilitation also results in desensitisation to dyspnoea [24], which may increase the symptomatic threshold for a COPD exacerbation [25]. Moreover, pulmonary rehabilitation has beneficial effects on mood status [26], daily activities [27] and self-efficacy [28]. This may all contribute to the observed decrease in hospital readmissions and the hospital length of stay after pulmonary rehabilitation $[29,30]$.

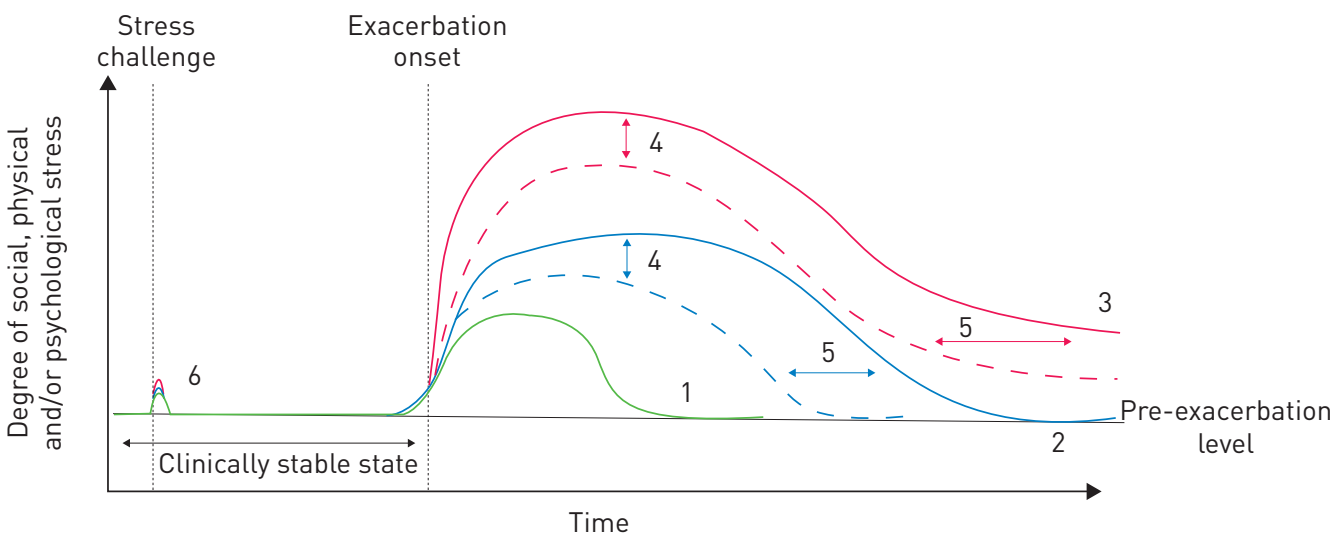

FIGURE 1 The impact of a chronic obstructive pulmonary disease (COPD) exacerbation. The figure shows hypothetical trajectories of the degree of social, physical and/or psychological stress of a COPD exacerbation over time. Solid green line: a low degree of stress after the onset of a COPD exacerbation; and an early recovery to pre-exacerbations stress levels (1). Solid blue line: a moderate degree of stress after the onset of a COPD exacerbation, and a late recovery to pre-exacerbation stress levels (2). Solid red line: a high degree of stress after the onset of a COPD exacerbation, and a defect in the recovery process that results in impaired health (3). Dotted blue and red line: a lower degree of stress after the onset of a COPD exacerbation (4) and a faster recovery (5) compared with a previous COPD exacerbation due to a comprehensive pulmonary rehabilitation programme. The figure also shows hypothetical trajectories of the response reaction to specific stress challenges (e.g. metabolic challenge [33] and/or host immune challenge [34]) (6). Ideally, this response would predict the degree of social, physical and/or psychological stress during a future exacerbation. 
Instead of searching for biomarkers of disease progression or disease activity [31], in order to improve the predictability of acute exacerbations, we may want to extend this research towards "biomarkers of health" [32], as in the ability to adapt and self-manage COPD-specific challenges, such as an exacerbation. Specific physical and/or metabolic stress tests may be useful to reflect the actual physical stress during and following an exacerbation [33,34]. Future research needs to identify the optimal set of measures to assess these exacerbation-related social, physical and psychological response reactions in patients with COPD. Ideally, the response to specific challenge stress tests in a pre-exacerbation state would predict the degree of social, physical and/or psychological stress during an exacerbation (figure 1). This will increase our understanding of the true impact of a COPD exacerbation, and, in turn, will provide guidance for the right combination of pharmacological and non-pharmacological therapies or even the development of "personalised preventive" strategies.

\section{References}

Huber M, Knottnerus JA, Green L, et al. How should we define health? BMJ 2011; 343: d4163.

2 Rodriguez-Roisin R. Toward a consensus definition for COPD exacerbations. Chest 2000; 117: Suppl. 2, 398S-401S.

3 Baker EH, Janaway CH, Philips BJ, et al. Hyperglycaemia is associated with poor outcomes in patients admitted to hospital with acute exacerbations of chronic obstructive pulmonary disease. Thorax 2006; 61: 284-289.

4 Markoulaki D, Kostikas K, Papatheodorou G, et al. Hemoglobin, erythropoietin and systemic inflammation in exacerbations of chronic obstructive pulmonary disease. Eur J Intern Med 2011; 22: 103-107.

5 Pavasini R, d'Ascenzo F, Campo G, et al. Cardiac troponin elevation predicts all-cause mortality in patients with acute exacerbation of chronic obstructive pulmonary disease: systematic review and meta-analysis. Int J Cardiol 2015; 191: 187-193.

6 Papi A, Bellettato CM, Braccioni F, et al. Infections and airway inflammation in chronic obstructive pulmonary disease severe exacerbations. Am J Respir Crit Care Med 2006; 173: 1114-1121.

7 Hurst JR, Vestbo J, Anzueto A, et al. Susceptibility to exacerbation in chronic obstructive pulmonary disease. N Engl J Med 2010; 363: 1128-1138.

8 Kessler R, Ståhl E, Vogelmeier C, et al. Patient understanding, detection, and experience of COPD exacerbations: an observational, interview-based study. Chest 2006; 130: 133-142.

9 Bendixen HJ, Waehrens EE, Wilcke JT, et al. Self-reported quality of ADL task performance among patients with COPD exacerbations. Scand J Occup Ther 2014; 21: 313-320.

$10 \mathrm{Ng}$ TP, Niti M, Tan WC, et al. Depressive symptoms and chronic obstructive pulmonary disease: effect on mortality, hospital readmission, symptom burden, functional status, and quality of life. Arch Intern Med 2007; 167: 60-67.

11 Papaioannou AI, Tsikrika S, Bartziokas K, et al. Collateral damage: depressive symptoms in the partners of COPD patients. Lung 2014; 192: 519-524.

12 Teixeira PJ, Porto L, Kristensen $\mathrm{CH}$, et al. Post-traumatic stress symptoms and exacerbations in COPD patients. COPD 2015; 12: 90-95.

13 van Ommen B, van der Greef J, Ordovas JM, et al. Phenotypic flexibility as key factor in the human nutrition and health relationship. Genes Nutr 2014; 9: 423.

14 Donaldson GC, Law M, Kowlessar B, et al. Impact of prolonged exacerbation recovery in chronic obstructive pulmonary disease. Am J Respir Crit Care Med 2015; 192: 943-950.

15 Seemungal TA, Donaldson GC, Bhowmik A, et al. Time course and recovery of exacerbations in patients with chronic obstructive pulmonary disease. Am J Respir Crit Care Med 2000; 161: 1608-1613.

16 van den Berge M, Hop WC, van der Molen T, et al. Prediction and course of symptoms and lung function around an exacerbation in chronic obstructive pulmonary disease. Respir Res 2012; 13: 44.

17 Agusti AG, Villaverde JM, Togores B, et al. Serial measurements of exhaled nitric oxide during exacerbations of chronic obstructive pulmonary disease. Eur Respir J 1999; 14: 523-528.

18 Høiseth AD, Neukamm A, Hagve TA, et al. The clinical value of serial measurement of high-sensitivity cardiac troponin T in acute exacerbations of chronic obstructive pulmonary disease. Open Heart 2014; 1: e000001.

19 FitzGerald JM, Poureslami I. The need for humanomics in the era of genomics and the challenge of chronic disease management. Chest 2014; 146: 10-12.

20 Lundman B, Aléx L, Jonsén E, et al. Inner strength - a theoretical analysis of salutogenic concepts. Int J Nurs Stud 2010; 47: 251-260.

21 Zwerink M, Brusse-Keizer M, van der Valk PD, et al. Self management for patients with chronic obstructive pulmonary disease. Cochrane Database Syst Rev 2014; 3: CD002990.

22 Spruit MA, Singh SJ, Garvey C, et al. An official American Thoracic Society/European Respiratory Society statement: key concepts and advances in pulmonary rehabilitation. Am J Respir Crit Care Med 2013; 188: e13-e64.

23 Mercken EM, Hageman GJ, Schols AM, et al. Rehabilitation decreases exercise-induced oxidative stress in chronic obstructive pulmonary disease. Am J Respir Crit Care Med 2005; 172: 994-1001.

24 Cooper CB. Desensitization to dyspnea in COPD with specificity for exercise training mode. Int J Chron Obstruct Pulmon Dis 2009; 4: 33-43.

25 Vestbo J, Lange P. Prevention of COPD exacerbations: medications and other controversies. ERJ Open Res 2015; 1: 00011-2015.

26 Trappenburg JC, Troosters T, Spruit MA, et al. Psychosocial conditions do not affect short-term outcome of multidisciplinary rehabilitation in chronic obstructive pulmonary disease. Arch Phys Med Rehabil 2005; 86: 1788-1792.

27 Sewell L, Singh SJ, Williams JE, et al. Can individualized rehabilitation improve functional independence in elderly patients with COPD? Chest 2005; 128: 1194-1200.

28 Vincent E, Sewell L, Wagg K, et al. Measuring a change in self-efficacy following pulmonary rehabilitation: an evaluation of the PRAISE tool. Chest 2011; 140: 1534-1539. 
29 Griffiths TL, Burr ML, Campbell IA, et al. Results at 1 year of outpatient multidisciplinary pulmonary rehabilitation: a randomised controlled trial. Lancet 2000; 355: 362-368.

30 Puhan MA, Gimeno-Santos E, Scharplatz M, et al. Pulmonary rehabilitation following exacerbations of chronic obstructive pulmonary disease. Cochrane Database Syst Rev 2011: CD005305.

31 Vestbo J, Anderson W, Coxson HO, et al. Evaluation of COPD longitudinally to identify predictive surrogate end-points (ECLIPSE). Eur Respir J 2008; 31: 869-873.

32 Stroeve $\mathrm{JH}$, van Wietmarschen $\mathrm{H}$, Kremer $\mathrm{BH}$, et al. Phenotypic flexibility as a measure of health: the optimal nutritional stress response test. Genes Nutr 2015; 10: 459.

33 Kardinaal AF, van Erk MJ, Dutman AE, et al. Quantifying phenotypic flexibility as the response to a high-fat challenge test in different states of metabolic health. FASEB J 2015; 29: 4600-4613.

34 Geelen TH, Gaajetaan GR, Wouters EF, et al. The host immune response contributes to Haemophilus influenzae virulence. Respir Med 2014; 108: 144-152. 